Case Report

\title{
Epiphysiolysis Type Salter I of the Medial Clavicle with Posterior Displacement: A Case Series and Review of the Literature
}

\author{
C. Siebenmann (D, F. Ramadani, G. Barbier, E. Gautier, and P. Vial \\ Department of Orthopedic Surgery, HFR Fribourg-Hôpital Cantonal, Switzerland \\ Correspondence should be addressed to C. Siebenmann; corinne.siebenmann@gmail.com
}

Received 7 May 2018; Accepted 29 August 2018; Published 27 September 2018

Academic Editor: Johannes Mayr

Copyright ( 2018 C. Siebenmann et al. This is an open access article distributed under the Creative Commons Attribution License, which permits unrestricted use, distribution, and reproduction in any medium, provided the original work is properly cited.

\begin{abstract}
Physeal fractures of the medial clavicle with posterior displacement of the metaphysis are very rare injuries, but additional injuries can be life-threatening. Due to the specific clavicular ossification process, skeletally immature patients present usually not true sternoclavicular joint (SCJ) dislocations accordingly to adults but rather displaced physeal fractures. There is no consensus in the current literature on the best treatment of this lesion. Conservative treatment is not resulting in good outcome; closed reduction is often not successful, and open reduction with internal fixation is finally required. Several methods are described for stabilizing these physeal fractures. We treated three osseous immature patients with this lesion. Due to the small dimension of the medial clavicular epiphysis, we performed in one case a transosseous figure-of-eight suture of the clavicular metaphysis towards the sternum, and in the two other cases, a transosseous suture from the clavicular metaphysis on the anterior clavicular periosteum. The latter technique avoids harm to the small epiphysis or the SCJ and minimizes the risk of retrosternal complications.
\end{abstract}

\section{Introduction}

Lesions of the sternoclavicular joint (SCJ) including epiphysiolyses type Salter I and II are rare in all age groups, representing less than $5 \%$ of all shoulder girdle injuries [1]. Posterior dislocations of the medial end of the clavicle in skeletally immature patients are exceptional. But, potential life-threating complications can occur due to the proximity to the trachea, esophagus, and retrosternal vascular and neural structures. In the literature, severe complications are reported resulting from missed diagnoses like cerebral insult due to vascular lesion [2] and compression of the trachea [3], the subclavian vessels [4], and the brachial plexus [5]; also, fatalities are documented due to a tracheoesophageal fistula [6].

An accurate diagnosis and appropriate treatment are therefore important for a good outcome [7]. Only few case reports or small case series exist in the current literature. These injuries are described as dislocation of the SCJ or epiphysiolysis of the medial end of the clavicle. The mechanism of injury is either a direct force applied to the medial clavicle or an indirect force due to an impact on the posterolateral aspect of the shoulder occurring often during contact sport activities [8].

The SCJ is functionally a saddle joint with a small surface providing only a poor congruence and containment. Therefore, a thick capsule and a strong ligamentous system guarantee joint stability. Spencer et al. showed on a cadaver model that the posterior capsule is the most important restraint for anterior and posterior translation in the SCJ [9]. Anterior dislocations occur nearly three times more often than posterior dislocations [10].

The understanding of the process of clavicular ossification is essential for an appropriate management of injuries around the SCJ in skeletally immature patients. The center of ossification of the medial end of the clavicle appears at the age of 18 to 20 years, and its growth plate fuses at the age of 20 to 25 years [11, 12].

Therefore, the physis of the medial clavicle is the weakest link in the SCJ and it is more likely to sustain a physeal separation than a true SCJ dislocation (Figures 1(a) and 1(b)). The strong ligamentous structures of the SCJ retain the cartilaginous epiphysis in place, and the metaphysis of the clavicle displaces posteriorly towards the retrosternal 


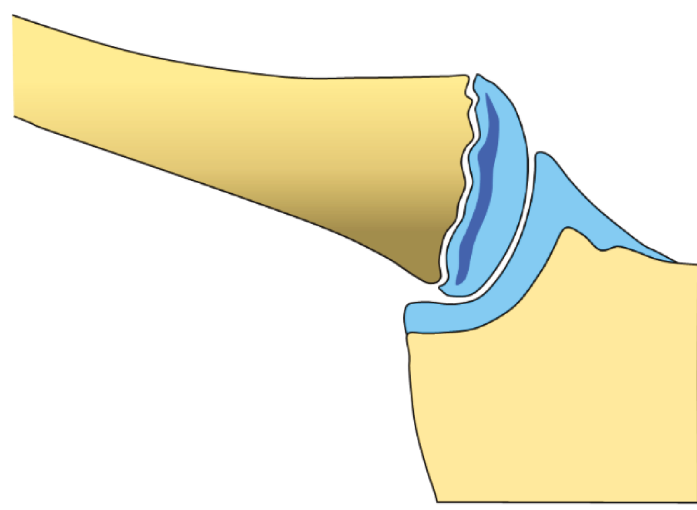

(a)

FIGURE 1: Sternoclavicular joint of an osseous immature person (a). Typical injury pattern: epiphysiolysis type Salter I with posterior displacement of the clavicular metaphysis (b).

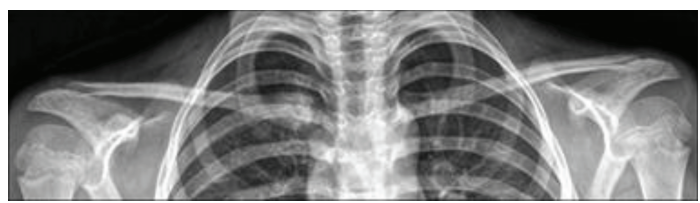

Figure 2: Preoperative anteroposterior radiographs revealing an asymmetric position of the medial clavicle on the right side.

space. On standard radiographs, the diagnosis of a SCJ lesion can be missed easily. Therefore, the clinical assessment of local pain and swelling and SCJ instability are important. To confirm the diagnosis and evaluate additional retrosternal injuries, further analysis using a CT scan is mandatory. However, even with a CT scan, discrimination between true SCJ dislocation and displaced epiphysiolysis type Salter I or II can be difficult [13-17]. Often, the final diagnosis is made during surgery [18].

In the current orthopedic literature, there are just a few case reports or small case series reported of the rare entity of epiphysiolysis of the medial clavicle.

Our objective is to propose an appropriate management of epiphysiolysis of the medial end of the clavicle in the skeletally immature patient.

\section{Cases}

We report on three patients suffering from traumatic epiphysiolysis of the medial clavicle and discuss the surgical management and fixation techniques.

In the first two cases-a 13-year-old boy and an 8-yearold girl, the mechanism of injury consisted in a lateral impact onto the involved shoulder while falling during a soccer play. In the third case of a 16-year-old boy, the mechanism was a direct blow in the anteroposterior direction on the upper thorax while practicing Judo. All three patients suffered from an instant pain in the right SCJ area. Clinically, no neurovascular lesions or dyspnea were present. Standard radiographs revealed an asymmetric position of the medial clavicle with

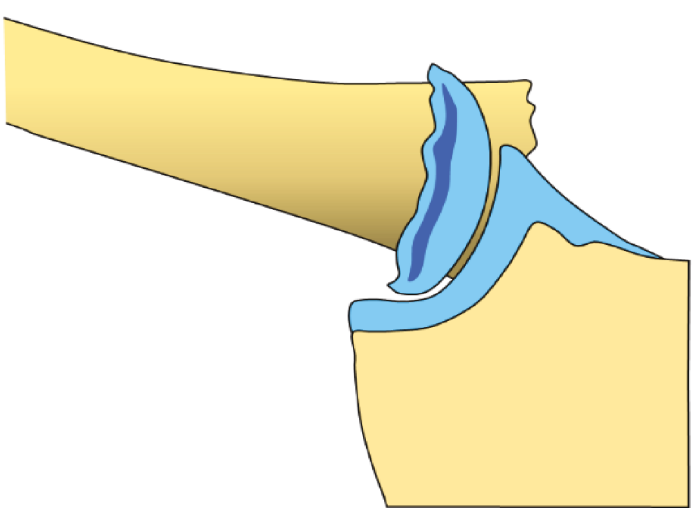

(b) posterior displacement of the medial end on the injured side (Figure 2). CT scan confirmed the diagnosis of epiphysiolysis of the medial clavicular epiphysis (Figures 3(a) and 3(b)). But, due to the absence of the corresponding centers of ossification of the medial clavicular epiphysis, discrimination from a pure posterior dislocation of the SCJ was difficult preoperatively, and final diagnosis was only possible during open surgery.

In the first child, an unsuccessful closed reduction was attempted prior to operation. The operation was performed under general anesthesia with the patient in supine position. A cushion was placed between the scapulae to exert tension on the anterior upper thorax. A $4 \mathrm{~cm}$ long skin incision was made in line with the clavicle from its medial end to the sternum. The periosteum, which was found intact anteriorly, was incised over the medial clavicle. The thick periosteal sleeve was disrupted posteriorly allowing posterior displacement of the medial clavicular metaphysis which was locked posterior to the manubrium. The medial clavicular epiphysis remained in place; thus, the lesion was classified as an epiphysiolysis type Salter I.

Reduction of the clavicle back in its periosteal sleeve was performed by gentle traction and the use of a pointed reduction clamp. Stabilization of the medial clavicular metaphysis was performed with a transosseous suture using a FiberTape $^{\circledR}$ in a figure-of-eight fashion from the clavicular metaphysis to the anterior cortex of the sternum.

Due to the experience of the first case in which the clavicular metaphysis was trapped behind the periosteal sleeve, surgical technique was adapted for the second and third children.

The skin incision was shorter, about $2 \mathrm{~cm}$ centered on the medial end of the clavicle. The platysma was just fenestrated. In both cases, the periosteal sleeve of the medial clavicle was found to be completely intact in its anterior part. It was incised longitudinally leaving intact the capsule of the SCJ. As seen in the first patient, the medial clavicular epiphysis stayed properly in place and the clavicular metaphysis was displaced retrosternally disrupting the posterior periosteum longitudinally. Open reduction was performed. Three drill 


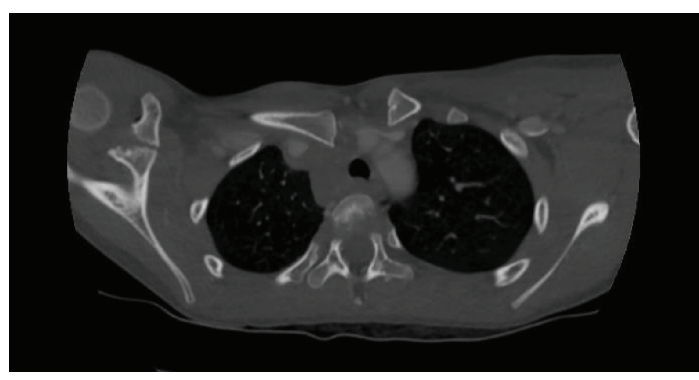

(a)

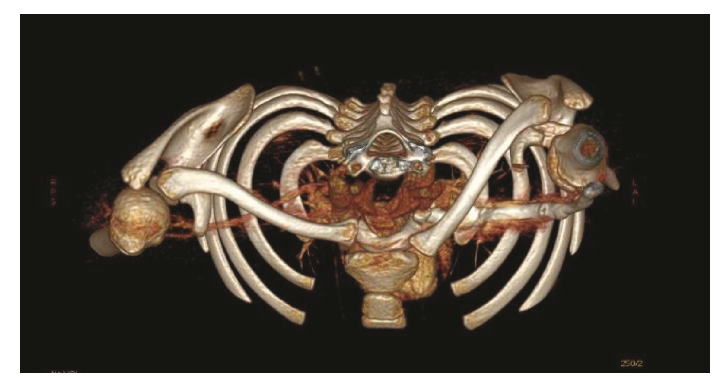

(b)

FIgURE 3: Axial (a) and three-dimensional reconstructed (b) computed tomography scans confirm the posteriorly displaced clavicle on the right side. Due to the absence of the corresponding centers of ossification of the medial clavicular epiphysis, discrimination from a pure posterior dislocation of the sternoclavicular joint is difficult.

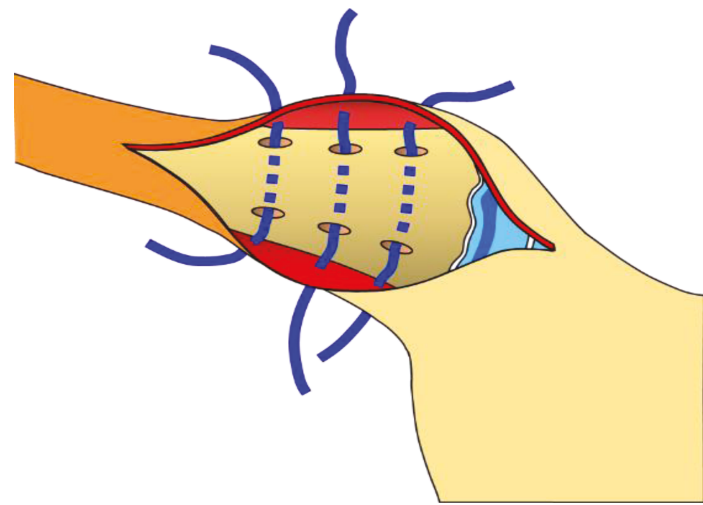

(a)

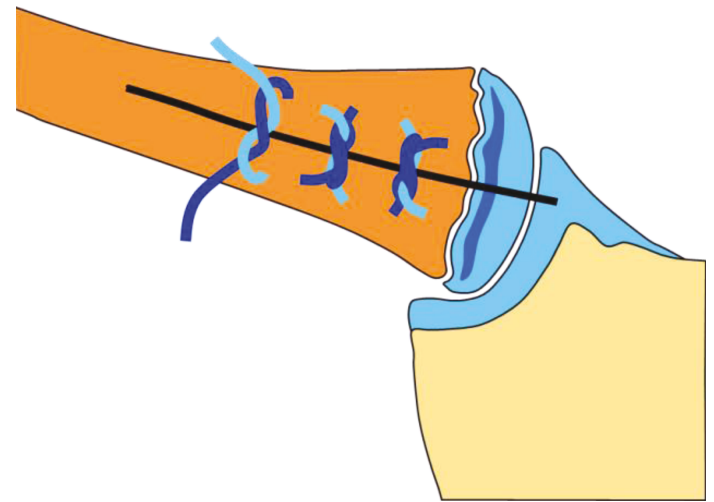

(b)

FiguRE 4: Surgical technique: fixation of the reduced clavicular metaphysis with three transosseous sutures (FiberWire ${ }^{\circledR}$ ) on the anterior clavicular periosteum (a). The clavicular metaphysis is fixed, and the periosteum is closed by tightening the knots (b).

holes were made in the superior and inferior cortex of the medial clavicular metaphysis avoiding perforation of the posterior cortex. Three FiberWire ${ }^{\circledR}$ were inserted in the holes, and the metaphysis was anchored directly to the strong and solid anterior clavicular periosteum (Figures 4(a) and 4(b)). Closure was completed in layers by additional adaptation of the anterior periosteum and the platysma.

Intraoperatively, in all three children, a good stability was achieved with the proposed suture techniques. No complications occurred during the operation. Facing the rare risk of severe vascular or pulmonal problems especially during the reduction maneuver, we assured backup by a thoracic surgeon in all cases.

Postoperatively, the patients were wearing a posterior figure-of-eight bandage for six weeks and free mobilization of the shoulder was allowed below the horizontal plane. At twelve weeks, all three patients were asymptomatic. The range of shoulder motion was symmetric; the body-cross test negative, and clinically the medial clavicle was stable. Radiographs revealed healing of the epiphysiolysis in correct length of the clavicle and correct position of the medial clavicular metaphysis. Also, at one-year follow-up, the patients remained asymptomatic and without any functional impairment, and all had returned to former sport activities.

\section{Discussion}

Actually, there is no consensus in the literature concerning the optimal treatment of this physeal fracture. Conservative treatment without anatomical reduction by thinking that the remodeling potential of immature bone would be able to restore correct anatomical position of the medial end of the clavicle is described in the past, but with reported complications like thoracic outlet syndrome by callus formation [19] and pneumothorax [20].

Denham and Dingley published probably one of the first reports of epiphyseal separation of the medial end of the clavicle. He favored an anatomical reduction to improve healing and decrease the number of poor results [21]. Closed reduction was recommended by several authors if there are no additional retrosternal injuries [16, 21-24]. However, the reported success rate was very diverging (Table 1). Often, an open reduction and internal fixation were required after a failed attempt of closed reduction or in case of residual instability [14, 23, 25-27]. Waters et al. [23] reviewed 13 medial clavicle injuries in skeletally immature patients and found 11 physeal fractures. They reported on instability after closed reduction in all cases and recommend immediate open reduction and fixation [23]. Laffosse et al. [14] reported a series of 13 patients with systematic failure of the attempted 
TABLE 1: Literature review (since 2000).

\begin{tabular}{lcccc}
\hline Author, year & $n$ & Age & Closed reduction & Definitive treatment \\
\hline Goldfarb et al., 2001 [25] & 6 & $7-16$ & 6 failed & 6 ORIF osteosuture \\
Waters et al., 2003 [23] & 11 & $13-17$ & 3 failed & 1 ORIF osteosuture \\
Gobet et al., 2004 [16] & 3 & $8-15$ & 2 successful & 1 ORIF osteosuture \\
Hofwegen and Wolf, 2008 [26] & 2 & $17-20$ & 1 failed & 5 nonoperative \\
Laffosse et al., 2010 [14] & 13 & $15-20$ & 7 failed & ORIF osteosuture \\
Tennent et al., 2012 [27] & 7 & $14-19$ & 1 failed & ORIF different techniques \\
Garg et al., 2012 [13] & 1 & 12 & 1 successful & ORIF osteosuture \\
Gil-Albarova et al., 2012 [34] & 1 & 11 & 0 & 1 ORIF osteosuture over SCJ \\
Koch and Wells, 2012 [29] & 1 & 14 & 2 failed & 1 ORIF osteosuture \\
Lee et al., 2014 [35] & & $13-19$ & 1 successful & 18 ORIF osteosuture \\
Ozer et al., 2014 [36] & 20 & 16 & 2 failed & 2 nonoperative \\
Tepolt et al., 2014 [18] & 1 & $7-17$ & 1 failed & 1 nonoperative \\
Perdreau et al., 2014 [37] & 6 & 16 & 0 & 6 osteosuture over SCJ \\
Krantzow, 2015 [38] & 1 & 17 & 0 & 1 osteosuture over SCJ \\
Kassé et al., 2016 [39] & 1 & 3 & & 1 osteosuture
\end{tabular}

closed reduction. They also recommend open reduction with a stabilization procedure [14].

The methods described for stabilizing these physeal fractures are quite different including fixation by Kirschner wires $[21]$, anterior plating $[17,28]$, or various suture techniques such as costoclavicular cerclage or tenodesis [14], repair of the costoclavicular and sternoclavicular ligaments [13, 23], transosseous fixation in a figure-of-eight manner of the clavicular metaphysis to the intact epiphysis [25, 29], or suturing the clavicle to the manubrium [18, 26, 30, 31]. The use of transarticular Kirschner wires has been abandoned due to the risk of intrathoracic wire migration [32].

Tennent et al. described a new stabilization technique [27]. After open reduction, they sutured the medial clavicle to the anterior periosteum and platysma as a single layer using absorbable sutures, which were passed through drill holes in the medial clavicle. At an average of nine months, their patients presented good functional results. Only one patient had to be reoperated six months after the initial procedure to remove a prominent suture knot and to revise the scar.

We are convinced that it is important to distinguish between a real dislocation of the SCJ and a physeal fracture of the medial end of the clavicle. Osseous immature patients suffer rather from physeal fracture type Salter I or II then from a pure dislocation of the SCJ. Nevertheless, these two entities are not every time properly discriminated in the literature, and in case of successful closed reduction and nonoperative treatment, the exact diagnosis will remain uncertain. We should keep in mind that in epiphysiolysis of the medial clavicle, the strong periosteal sleeve plays an important role. Corresponding to lateral physeal fracture, the clavicle peels off from its physis and periosteal sleeve, which is just disrupted longitudinally [33].
In all our three cases, the medial epiphysis remained anatomically in place, and the clavicular metaphysis was displaced posteriorly to it into the retrosternal space. In all three cases, the periosteal sleeve was only disrupted posteriorly allowing the posterior penetration of the medial clavicular end.

Due to its small dimension, the medial clavicular epiphysis itself does not offer sufficient grip for anchoring sutures. Thus, two different options to restore stability of the medial clavicle are available. The first one consists in a transosseous figure-of-eight suture of the clavicular metaphysis towards the anterior cortex of the sternum. The second one is comparable to the technique described by Tennent et al. [27]. The anteriorly intact periosteal sleeve is incised, the clavicular metaphysis reduced back into its sleeve, and held in place by means of three transosseous sutures from the clavicular metaphysis on the anterior clavicular periosteum. In contrast to the technique described by Tennent et al., we did not include the platysma in the suture allowing a better coverage of the knots by the platysma. In addition, instead of PDS, we used FiberWire ${ }^{\circledR}$, thus creating less prominent knots.

We attempted a closed reduction in the first patient which failed because the metaphysis was stucked outside the periosteal sleeve posterior to the epiphysis as seen later intraoperatively. This finding agrees with the literature review shown in Table 1, which suggests that a closed reduction is rarely successful. Even if the patients do not present further initial symptoms, in our opinion, an immediate (up to $6 \mathrm{~h}$ ) open reduction and fixation are indicated to avoid injuries of retrosternal structures by either the instable fragment or callus formation.

In contrast, when physeal fracture of the medial clavicle with anterior displacement occurs, a conservative treatment is often recommended. In this case, the periosteal sleeve is 
just disrupted anteriorly and stays intact posteriorly, which protects the mediastinal structures.

The advantage of the described methods is that neither the fragile epiphysis nor the SCJ is violated, the retrosternal structures are safe, and there is no hardware irritation. Mechanically, the clavicular metaphysis buttresses against the clavicular epiphysis, and the transosseous sutures into the anterior periosteum prevent the posterior redislocation. The bone is also loaded in compression, and the restored anterior periosteum plays the role of a tension band.

We practiced both stabilization techniques. Both had excellent clinical and radiographical results at one year. Nevertheless, we recommend the second one stabilizing the clavicula on the anterior periosteum, because it is technically simpler and safer referring to possible iatrogenic retrosternal injuries.

\section{Conflicts of Interest}

The authors declare that there are no conflicts of interest regarding the publication of this paper.

\section{References}

[1] E. F. Cave, Fractures and Other Injuries, Year Book Publishers, 1958.

[2] M. S. Marcus and V. Tan, "Cerebrovascular accident in a 19-year-old patient: a case report of posterior sternoclavicular dislocation," Journal of Shoulder and Elbow Surgery, vol. 20, no. 7, pp. e1-e4, 2011.

[3] E. Nakayama, T. Tanaka, T. Noguchi, J. Yasuda, and Y. Terada, "Tracheal stenosis caused by retrosternal dislocation of the right clavicle," The Annals of Thoracic Surgery, vol. 83, no. 2, pp. 685-687, 2007.

[4] N. W. Emms, A. D. Morris, J. C. Kaye, and S. D. Blair, "Subclavian vein obstruction caused by an unreduced type II Salter Harris injury of the medial clavicular physis," Journal of Shoulder and Elbow Surgery, vol. 11, no. 3, pp. 271-273, 2002.

[5] S. Jain, D. Monbaliu, and J. F. Thompson, "Thoracic outlet syndrome caused by chronic retrosternal dislocation of the clavicle. Successful treatment by transaxillary resection of the first rib," Journal of Bone and Joint Surgery. British Volume (London), vol. 84, pp. 16-118, 2002.

[6] M. J. Wasylenko and E. F. Busse, "Posterior dislocation of the clavicle causing fatal tracheoesophageal fistula," Canadian Journal of Surgery, vol. 24, pp. 626-627, 1981.

[7] K. D. Carmichael, A. Longo, S. Lick, and L. Swischuk, "Posterior sternoclavicular epiphyseal fracture-dislocation with delayed diagnosis," Skeletal Radiology, vol. 35, no. 8, pp. 608-612, 2006.

[8] C. T. Buckerfield and M. E. Castle, "Acute traumatic retrosternal dislocation of the clavicle," Journal of Bone and Joint Surgery, vol. 66, no. 3, pp. 379-385, 1984.

[9] E. E. Spencer, J. E. Kuhn, L. J. Huston, J. E. Carpenter, and R. E. Hughes, "Ligamentous restraints to anterior and posterior translation of the sternoclavicular joint," Journal of Shoulder and Elbow Surgery, vol. 11, no. 1, pp. 43-47, 2002.

[10] M. S. Bahk, J. E. Kuhn, L. M. Galatz, P. M. Connor, and G. R. Wiliams Jr., "Acromioclavicular and sternoclavicular injuries and clavicular, glenoid, and scapular fractures," The Journal of Bone and Joint Surgery, vol. 91-A, pp. 2492-2510, 2009.

[11] C. F. Heinig, "Retrosternal dislocation of the clavicle: early recognition, X-ray diagnosis, and management," The Journal of Bone and Joint Surgery, vol. 50-A, p. 830, 1968.

[12] J. Y. Bishop and E. L. Flatow, "Pediatric shoulder trauma," Clinical Orthopaedics and Related Research, vol. 432, no. 432, pp. 41-48, 2005.

[13] S. Garg, Z. A. Alshameeri, and W. A. Wallace, "Posterior sternoclavicular joint dislocation in a child: a case report with review of literature," Journal of Shoulder and Elbow Surgery, vol. 21, no. 3, pp. e11-e16, 2012.

[14] J. M. Laffosse, A. Espie, N. Bonnevialle et al., "Posterior dislocation of the sternoclavicular joint and epiphyseal disruption of the medial clavicle with posterior displacement in sports participants," The Journal of Bone and Joint Surgery, vol. 92-B, no. 1, pp. 103-109, 2010.

[15] F. H. Selesnick, M. Jablon, C. Frank, and M. Post, "Retrosternal dislocation of the clavicle. Report of four cases," The Journal of Bone and Joint Surgery, vol. 66, no. 2, pp. 287-291, 1984.

[16] R. Gobet, M. Meuli, S. Altermatt, V. Jenni, and U. V. Willi, "Medial clavicular epiphysiolysis in children: the so-called sterno-clavicular dislocation," Emergency Radiology, vol. 10, no. 5, pp. 252-255, 2004.

[17] W. M. Franck, R. M. Siassi, and F. F. Hennig, "Treatment of posterior epiphyseal disruption of the medial clavicle with a modified balser plate," The Journal of Trauma: Injury, Infection, and Critical Care, vol. 55, no. 5, pp. 966-968, 2003.

[18] F. Tepolt, P. M. Carry, P. C. Heyn, and N. H. Miller, "Posterior sternoclavicular joint injuries in the adolescent population: a meta-analysis," The American Journal of Sports Medicine, vol. 42, no. 10, pp. 2517-2524, 2014.

[19] D. M. Gangahar and T. Flogaites, "Retrosternal dislocation of the clavicle producing thoracic outlet syndrome," The Journal of Trauma, vol. 18, no. 5, pp. 369-372, 1978.

[20] L. W. Worman and C. Leagus, "Intrathoracic injury following retrosternal dislocation of the clavicle," The Journal of Trauma, vol. 7, no. 3, pp. 416-423, 1967.

[21] R. H. Denham and A. F. Dingley, "Epiphyseal separation of the medial end of the clavicle," The Journal of Bone \& Joint Surgery, vol. 49, no. 6, pp. 1179-1183, 1967.

[22] J. Yang, H. al-Etani, and M. Letts, "Diagnosis and treatment of posterior sternoclavicular joint dislocations in children," The American Journal of Orthopedics, vol. 25, no. 8, pp. 565-569, 1996.

[23] P. M. Waters, D. S. Bae, and R. K. Kadiyala, "Short-term outcomes after surgical treatment of traumatic posterior sternoclavicular fracture-dislocations in children and adolescents," Journal of Pediatric Orthopedics, vol. 23, no. 4, pp. 464-469, 2003.

[24] K. R. Zaslav, S. Ray, and C. S. Neer 2nd, "Conservative management of a displaced medial clavicular physeal injury in an adolescent athlete. A case report and literature review," The American Journal of Sports Medicine, vol. 17, no. 6, pp. 833836, 1989.

[25] C. A. Goldfarb, G. S. Bassett, S. Sullivan, and J. E. Gordon, "Retrosternal displacement after physeal fracture of the medial clavicle in children treatment by open reduction and internal fixation," The Journal of Bone and Joint Surgery, vol. 83-B, no. 8, pp. 1168-1172, 2001. 
[26] C. V. Hofwegen and B. Wolf, "Suture repair of posterior sternoclavicular physeal fractures: a report of two cases," The Iowa Orthopaedic Journal, vol. 28, pp. 49-52, 2008.

[27] T. D. Tennent, E. O. Pearse, and D. M. Eastwood, "A new technique for stabilizing adolescent posteriorly displaced physeal medial clavicular fractures," Journal of Shoulder and Elbow Surgery, vol. 21, no. 12, pp. 1734-1739, 2012.

[28] H. Asfazadourian and J. F. Kouvalchouk, "Retrosternal luxation of the clavicle. Apropos of 4 cases surgically treated using a temporary screwed anterior plate and review of the literature," Annales de Chirurgie de la Main, vol. 16, pp. 152-169, 1997.

[29] M. J. Koch and L. Wells, "Proximal clavicle physeal fracture with posterior displacement: diagnosis, treatment and prevention," Orthopedics, vol. 35, pp. e108-e111, 2012.

[30] E. Aydin, T. C. Dülgeroglu, A. Ates, and H. Metineren, "Repair of unstable posterior sternoclavicular dislocation using nonabsorbable tape suture and tension band technique: a case report with good results," Case Reports in Orthopedics, vol. 2015, Article ID 750898, 3 pages, 2015.

[31] D. P. Thomas, P. R. Williams, and H. C. Hoddinott, ““A safe” surgical technique for stabilization of the sternoclavicular joint: a cadaveric and clinic study," Annals of the Royal College of Surgeons, vol. 82, pp. 432-435, 2000.

[32] N. Venissac, M. Alifano, M. Dahan, and J. Mouroux, "Intrathoracic migration of Kirschner pins," The Annals of Thoracic Surgery, vol. 69, no. 6, pp. 1953-1955, 2000.

[33] J. A. Ogden, "Distal clavicular physeal injury," Clinical Orthopaedics and Related Research, vol. 188, no. 188, pp. 68-73, 1984.

[34] J. Gil-Albarova, S. Rebollo-González, V. E. Gómez-Palacio, and A. Herrera, "Management of sternoclavicular dislocation in young children: considerations about diagnosis and treatment of four cases," Musculoskeletal Surgery, vol. 97, no. 2, pp. 137-143, 2013.

[35] J. T. Lee, A. Y. Nasreddine, E. M. Black, D. S. Bae, and M. S. Kocher, "Posterior sternoclavicular joint injuries in skeletally immature patients," Journal of Pediatric Orthopedics, vol. 34, no. 4, pp. 369-375, 2014.

[36] U. E. Ozer, M. B. Yalçin, K. Kanberoglu, and A. E. Bagatur, "Retrosternal displacement of the clavicle after medial physeal fracture in an adolescent: MRI," Journal of Pediatric Orthopedics B, vol. 23, no. 4, pp. 375-378, 2014.

[37] A. Perdreau, B. Bingen, L. Gossing, E. Lejeune, and A. Beugnies, "Posterior sternoclavicular epiphyseal fracturedislocation: case report and review of literature," Injury Extra, vol. 45, no. 1, pp. 1-5, 2014.

[38] M. Krantzow, "Medial clavicle physeal fracture: a case report from diagnosis to treatment," The Orthopod, vol. 14, 2015.

[39] A. N. Kassé, S. O. Limam, S. Diao, J. C. Sané, B. Thiam, and M. H. Sy, "Fracture-separation of the medial clavicular epiphysis: about 6 cases and review of the literature," The Pan African Medical Journal, vol. 25, p. 19, 2016. 


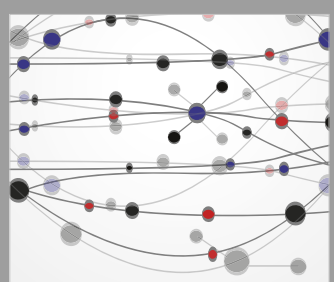

The Scientific World Journal
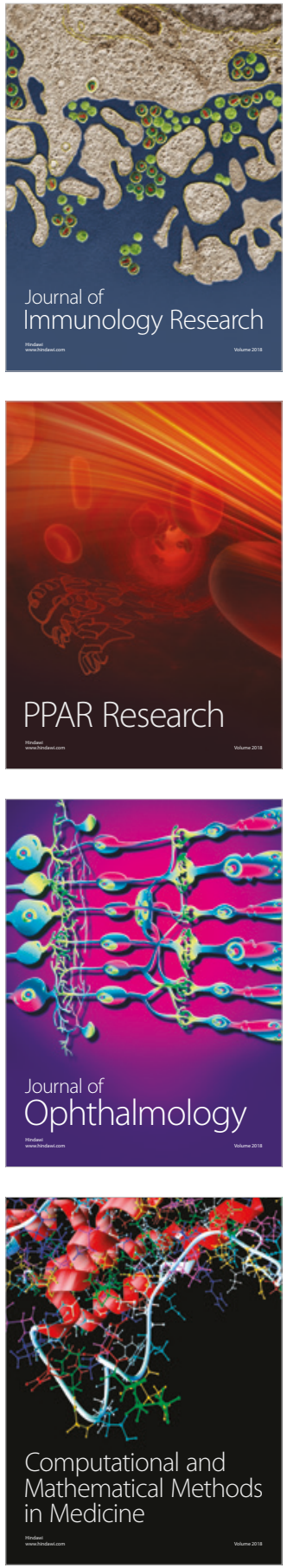

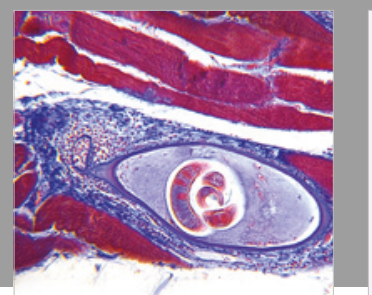

Gastroenterology Research and Practice

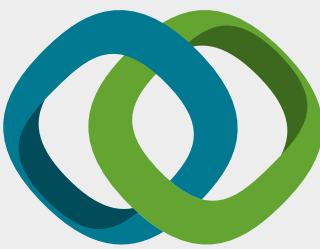

\section{Hindawi}

Submit your manuscripts at

www.hindawi.com
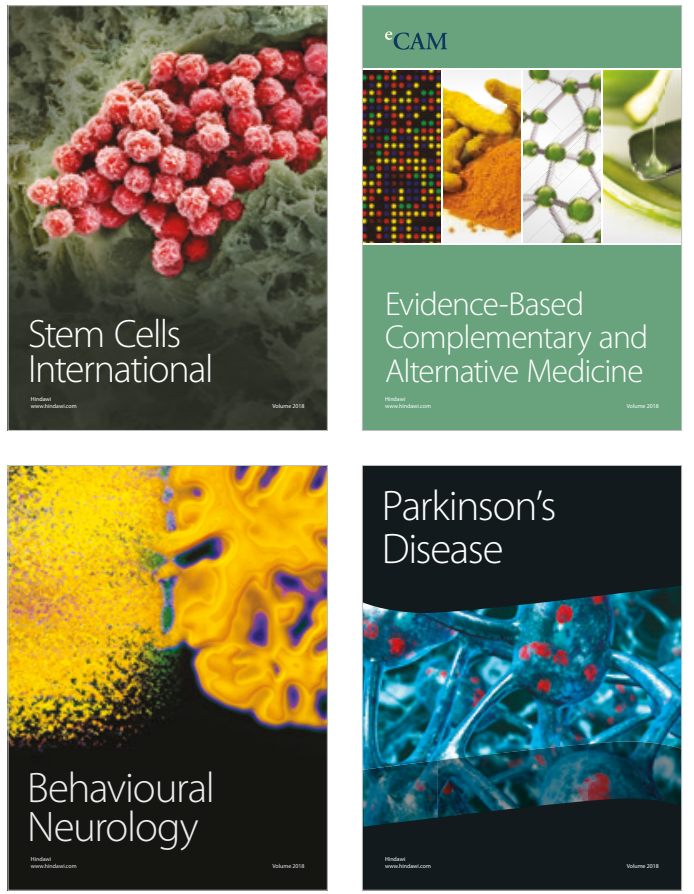

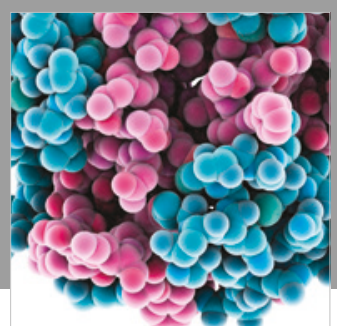

ournal of

Diabetes Research

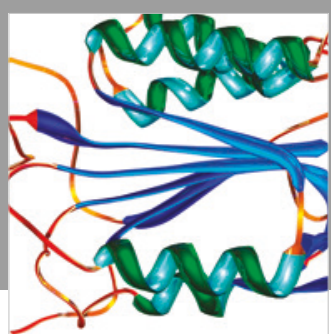

Disease Markers
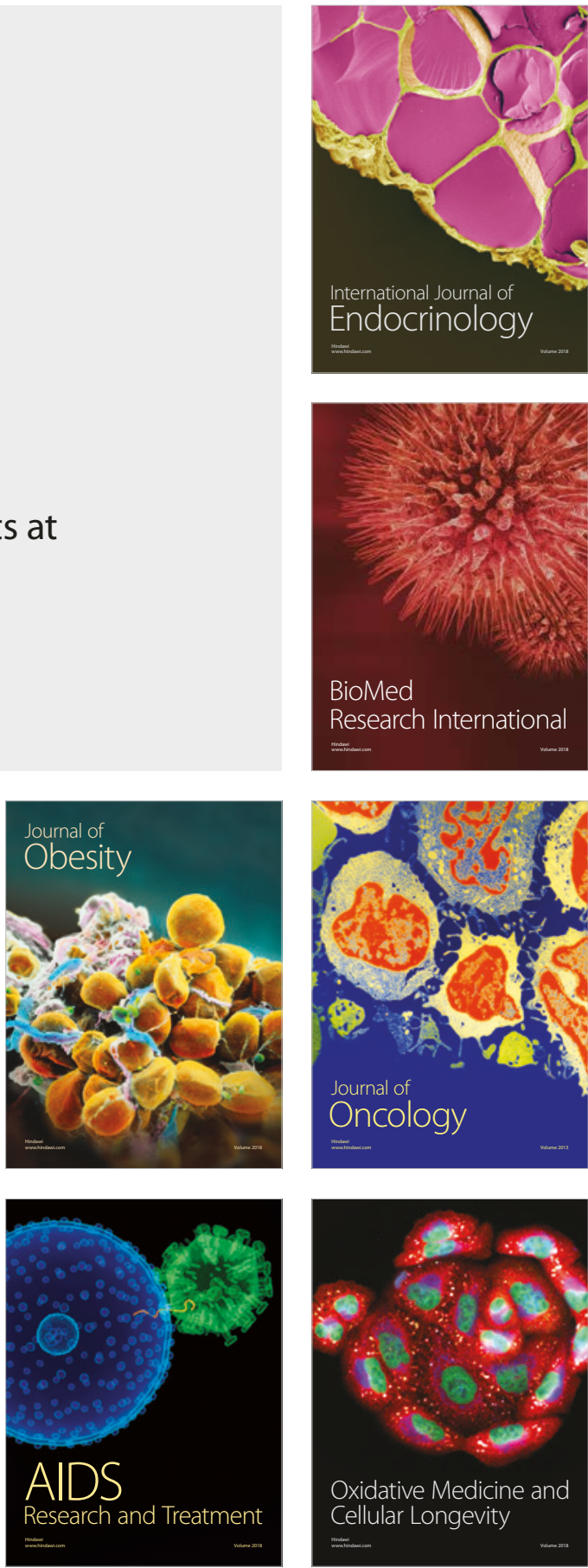